\title{
SQUIRE and the evolving science of healthcare improvement
}

\section{David P Stevens}

Correspondence to

Dr David P Stevens, The Dartmouth Institute for Health Policy and Clinical Practice, PO Box 678, Chilmark, MA 02535, USA; david.p.stevens@dartmouth.edu

Accepted 5 March 2015 Published Online First 27 March 2015

\section{SLinked}

http://dx.doi.org/10.1136/ bmjqs-2014-003737

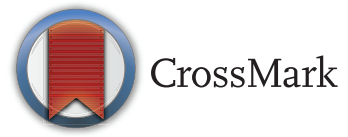

To cite: Stevens DP. BMJ Qual Saf 2015;24:349-351.
The SQUIRE (Standards for QUality Improvement Reporting Excellence) guidelines seek to improve the reporting of studies of healthcare improvement work, ${ }^{1}$ but are interventions in a field of science that is itself rapidly evolving. ${ }^{2-4}$ SQUIRE differs in this regard from reporting guidelines for studies that are based on more stable methodologies, for example, randomised clinical trials (CONSORT) or systematic reviews (PRISMA).

SQUIRE in 2008 probed relatively unfamiliar territory for editors, reviewers and authors, including those associated with journals apparently focused on healthcare improvement. The pilot study reported by Howell et $a l^{5}$ offers a perspective on that interaction. They counted the number of SQUIRE elements that appeared in four selected journals before (2006-2008) and after (20102012) publication of SQUIRE. Included among the journals were 3 of the 17 journals that suggest using the guidelines. ${ }^{6}$ They found no difference in SQUIRE elements in this relatively small study sample. These findings are in contrast with the positive effect that was reported when an early version of CONSORT guidelines for clinical trials was assessed. ${ }^{7}$ This different outcome may be related to more articles and higher impact journals examined over a longer study period in the CONSORT evaluation.

In any event, a report such as that by Howell et al, raises by implication questions that may apply uniquely to editorial expectations and publication guidelines for an evolving science. Well before manuscript preparation, how do authors use SQUIRE for design of their improvement initiatives-including the planning of the studies and incorporation of appropriate methodologies-that are conveyed in their reports? How does the aspiring author apply publication guidelines when the field itself is actively evolving? Given the dynamic state that characterises the epistemology of healthcare improvement, ${ }^{89}$ should editors and reviewers require all items on the guidelines checklist, or are some mandatory only for selected categories of improvement reports?

\section{8: WHAT IS A HEALTHCARE IMPROVEMENT REPORT?}

In 2008 there was little agreement about what constituted a scholarly healthcare improvement report, and a proposed typology described considerable variation. ${ }^{10}$ Editorial expectations for such reports have subsequently evolved, ${ }^{11}$ paralleling the development of insights into the science of healthcare improvement. ${ }^{2-4}$

Standards had been proposed in 1999 for Quality Improvement Reports (QIR). ${ }^{12}$ A QIR was a case report of a local improvement initiative that might be adapted and implemented in readers' settings. By 2008, the QIR format had been employed in over 50 published reports, principally in $B M J$-sponsored journals (Koplan KE, unpublished, 2008).

Draft publication guidelines to advance scientific rigour for the work of authors, editors and reviewers were proposed in $2005^{13}$ and led to a consensus-based report of SQUIRE as a content checklist in $2008 .^{1}$ At that time the authors of SQUIRE cautioned, "The SQUIRE Guidelines...must always be used as signposts, not shackles. This caution probably translates best into practice if authors keep the guidelines in mind as a general framework while writing their initial draft, and then use them for detailed critical appraisal of what they've written while they revise the text." 1

Indeed it was apparent early that slavish adherence to the newly available SQUIRE checklist resulted in long, even monotonous manuscripts-borne out when the editors of Quality and Safety in Health Care (the ancestor journal of $B M J$ Quality and Safety) invited authors of papers that were undergoing revision to 
test the new guidelines. ${ }^{14}$ Revisions of three such papers led reviewers to advise their authors to be more selective in their application of SQUIRE elements in the final published papers. ${ }^{15-17}$ (Stevens DP, unpublished, 2009).

\section{REPORTING GUIDELINES FOR AN EMERGING SCIENCE}

\section{Strength of evidence, theory and context}

Critical analysis of what actually has happened in an author's healthcare improvement initiative-and, more importantly, why and how-inevitably draws on scholarly fields beyond biomedical science including the wide range of social sciences and organisation research. ${ }^{8} 18$ Moreover, boundaries are increasingly permeable among the epistemologies of healthcare improvement, health services research and the social sciences. $^{2} 38$

At least three elements of a healthcare improvement report have emerged in greater focus since the original SQUIRE publication. As healthcare improvement scholars and practitioners become increasingly unambiguous about the underpinning discipline of healthcare improvement, strength of evidence, ${ }^{2} 19$ the theories that underlie improvement efforts ${ }^{20}$ and empirical evidence for the role of context, ${ }^{21-23}$ appear to be fundamental for such a report.

\section{Strength of evidence}

SQUIRE's emphasis on the clear statement of a report's critical study question with supporting evidence $^{1}$ - appearing simple on its face-in fact in 2008 constituted a radical pivot to the critical study of the improvement itself and its outcomes. The SQUIRE elements that explored the study question invited the author to go beyond the description of the improvement initiative per se to define the research question that offered evidence for the effect of the initiative on patient care or a health system. It asked for critical measurement of the improvement and its associated outcomes, which in turn required supporting statistical methodology. 219

\section{Theory that underlies the improvement}

There were early calls for description of the theory on which an improvement initiative was based. ${ }^{24}$ This evolved increasingly into an explicit expectation for hypotheses that underlie an improvement intervention in its commitment to improving patient care or a health system-what some authors have called 'reason-giving'. ${ }^{20}$ Such analysis demands deeper exploration of the social components of context that provide the drivers and barriers to implementation. Dixon-Woods et $a l^{25}$ provide the most salient example of the complexity of post hoc theory development in their analysis of the successful Michigan Intensive Care Unit central line initiative by Pronovost et $a l^{26}$ Critical analysis of what was intended, or supposed to happen, inevitably draws on scholarly fields beyond biomedical science, including the wide range of social sciences. $^{25}$

\section{Context}

The interaction between an improvement initiative and the context in which it occurs lies at the very heart of healthcare improvement. ${ }^{27}$ Context is a mutable part of the social process that is healthcare improvement in contrast to biologically active clinical interventions where context must be rigidly controlled. ${ }^{28}$ To this end, Kaplan et $a l^{21}$ and others ${ }^{22} 23$ have emphasised the importance of an author's empirical evidence for the critical contribution of context to an improvement initiative. These reports underscored that few scholarly improvement reports have heretofore contained such evidence.

This critical focus offers a fresh challenge for improvement authors. It goes well beyond broad description of the physical and organisational attributes of a clinical setting to address context's wider scope-leadership, external regulations, hierarchy and other issues that influence the social context of improvement. $^{2122}$

\section{THE PROMISE OF SQUIRE 2.0-WITH ONE CAUTION}

\section{Broadening dissemination of SQUIRE}

There is currently a consensus-based revision process underway which will produce SQUIRE 2.0. ${ }^{29}$ The aim is to capture the promise of SQUIRE to address the emerging science of healthcare improvement including elements such as strength of evidence, theory and context. It will be particularly important to make SQUIRE continually more useful for authors, editors and reviewers. It should include dissemination to wider specialties and more diverse journals.

A new version should also call for avoidance of the straitjacket against which the original SQUIRE authors cautioned. ${ }^{1}$ Improvement reports increasingly are emerging from diverse healthcare fields that embrace diverse methodologies, and the risk of overly rigorous implementation could inadvertently lead SQUIRE to limit innovation. This requires a balance of the strengths of traditional quality improvement methodologies with those of sensibly crafted innovative improvement initiatives-perhaps methodologies that are not even currently apparent. One practical strategy will be wider employment of SQUIRE as an anchor for formal teaching and coaching about writing, which offers a pragmatic test bed for how and where SQUIRE fits in the design of improvement initiatives and the preparation of useful manuscripts. ${ }^{11} 30$ Ultimately, the many stakeholders in healthcare improvement including clinicians, improvement specialists, methodologists, statisticians, editors, reviewers and readers will be the arbiters of the essential elements of a scholarly improvement report. 
Acknowledgements The author thanks Frank Davidoff and Paul Batalden for comments on a draft of this editorial.

Competing interests The author is a member of the SQUIRE Development Group for which he receives an honorarium and travel support from The Health Foundation and Robert Wood Johnson Foundation. He is Editor Emeritus of BMJ Quality and Safety.

\section{Competing interests None.}

Provenance and peer review Not commissioned; internally peer reviewed.

\section{REFERENCES}

1 Davidoff F, Batalden P Stevens D, et al. Publication guidelines for quality improvement in health care: evolution of the SQUIRE project. Qual Saf Health Care 2008;17(Suppl 1):i3-9.

2 Shojania KG, Grimshaw JM. Evidence-based quality improvement: the state of the science. Health Aff (Millwood) 2005;24:138-50.

3 Auerbach AD, Landefeld CS, Shojania KG. The tension between needing to improve care and knowing how to do it. N Engl J Med 2007;357:608-13.

4 Marshall M, Pronovost P, Dixon-Woods M. Promotion of improvement as a science. Lancet 2013;381:419-21.

5 Howell V, Schwartz AE, O'Leary JD, et al. The effect of the SQUIRE (Standards for QUality Improvement Reporting Excellence) guidelines on reporting standards in the quality improvement literature: a before-and-after study. BMJ Qual Saf 2015;24:400-6.

6 http://www.squire-statement.org/resources/journals (accessed 18 Feb 2015).

7 Moher D, Jones A, Lepage L. Use of the CONSORT statement and quality of reports of randomized controlled trails: a comparative before-and-after evaluation. JAMA 2001;285: 1992-5.

8 Knowledge for Improvement. Papers from the Vin McLoughlin symposium on the epistemology of improving health care, April 12-16, 2010. BMJ Qual Saf 2011;20(Supp 1):i1-i104.

9 Perla RJ, Provost LP, Parry GJ. Seven propositions of the science of improvement: exploring foundations. Qual Manag Health Care 2013;20:170-86.

10 Rubenstein LV, Hempel S, Farmer MM, et al. Finding order in heterogeneity: types of quality-improvement intervention publications. Qual Saf Health Care 2008;17:403-8.

11 Holzmueller CG, Pronovost PJ. Organising a manuscript reporting quality improvement or patient safety research. BMJ Qual Saf 2013;22:777-85.

12 Moss F, Thomson RG. A new structure for quality improvement reports. Qual Health Care 1999;8:76.

13 Davidoff F, Batalden P. Toward stronger evidence on quality improvement. Draft publication guidelines: the beginning of a consensus project. Qual Saf Health Care 2005;14:319-25.
14 Stevens DP, Thomson R. SQUIRE arrives-with a plan for its own improvement. Qual Saf Health Care 2008;17(Suppl 1): i1-2.

15 Bechtold ML, Scott S, Nelson K, et al. Educational quality improvement report: outcomes from a revised morbidity and mortality format that emphasized patient safety. Qual Saf Health Care 2007;16:422-7.

16 Kirsh SR, Aron DC. Integrating the chronic-care model and the ACGME competencies: using shared medical appointments to focus on systems-based practice. Qual Saf Health Care 2008;17:15-19.

17 Hoffman KG, Brown RMA, Gay JW, et al. How an educational improvement project improved the summative evaluation of medical students. Qual Saf Health Care 2009;18:283-7.

18 Bate P, Mendel P, Robert G. Organizing for quality. the improvement journeys of leading hospitals in Europe and the United States. Radcliffe Publishing 2008. 252 pp.

19 Parry GJ, Carson-Stevens A, Luff DF, et al. Recommendations for evaluation of health care initiatives. Acad Pediatr 2013;13: S23-30.

20 Davidoff F, Dixon-Woods M, Leviton L, et al. Demystifying theory and its use in improvement. BMJ Qual Saf 2015;24:228-38.

21 Kaplan HC, Brady PW, Dritz MC, et al. The influence of context on improvement success in health care: a systematic review of the literature. Milbank Q 2010;88:500-59.

22 Taylor SL, Dy S, Foy R, et al. What context features might be important determinants of the effectiveness of patient safety interventions? BMJ Qual Saf 2011;20:611-17.

23 Stevens DP, Shojania KG. Tell me about the context, and more. BMJ Qual Saf 2011;20:557-9.

24 Walshe K. Understanding what works - and why-in quality improvement: the need for theory-driven evaluation. Int $J$ Qual Health Care 2007;19:57-9.

25 Dixon-Woods M, Bosk CL, Aveling E-L, et al. Explaining Michigan: developing an ex post theory of a quality improvement program. Milbank Q 2011;89:167-205.

26 Pronovost P, Needham D, Berenholtz S, et al. An intervention to decrease catheter-related bloodstream infections in the ICU. New Eng J Med 2006;355:2725.

27 Batalden PB, Davidoff F. What is "quality improvement" and how can it transform health care. Qual Saf Health Care 2007;16:2-3.

28 Davidoff F. Improvement interventions are social treatments, not pills. Ann Intern Med 2014;161:526-7.

29 Davies L, Ogrinc G. New SQUIRE publication guidelines: supporting nuanced reporting and reflection on complex interventions. BMJ Qual Saf 2015;24:184-5.

30 Stevens DP, Marshall BC. Healthcare improvement is incomplete until it is published: the cystic fibrosis initiative to support scholarly publication. BMJ Qual Saf 2014;23:i104-7. 